\title{
DESIGN CENOGRÁFICO: UM OLHAR DO DESIGN PARA A CENOGRAFIA EM BALÉ DE REPERTÓRIO
}

Débora de Oliveira Samarino

Universidade do Estado de Minas Gerais

dedesamarino@gmail.com

Giselle Hissa Safar

Universidade do Estado de Minas Gerais

Yuri Simon da Silveira

Universidade do Estado de Minas Gerais

Resumo: $O$ presente estudo teve por objetivo analisar e discutir a abordagem do design cenográfico relacionado com a cenografia em balés de repertório por meio do confronto de diversos autores das áreas que englobam esse universo e se justifica pela oportunidade de aprofundamento no tema, pela necessidade de abordagem pelos assuntos referentes à cenografia como atividade projetual e pelo potencial de atuação do profissional de design nessa área. Partiu-se da hipótese que a cenografia de um espetáculo de dança consiste em um projeto e como tal envolve procedimentos metodológicos que o configuram como atividade de design e coautora da cena de dança, por constituir parte integrante de sua concepção e colaborar na construção de sentidos da composição artística. Metodologicamente, o projeto consistiu numa pesquisa qualitativa do tipo descritivo e explicativo, os procedimentos para a realização do estudo proposto se dividem em duas etapas que consistem em: pesquisa bibliográfica para o aprofundamento da compreensão dos conceitos envolvidos e a análise, descrição e comparação da produção cenográfica do balé de repertório Don Quixote feito por duas companhias de balé clássico, uma nacional de concepção artística e outra internacional de concepção projetual cenográfica. Ao final desta elaboração confirmouse a premissa original da pesquisa de que a cenografia em espetáculos de dança consiste em uma atividade de design e age, também, como coautora da cena de dança.

Palavras-chave: design, design cenográfico, cenografia, balé de repertório e Don Quixote. 


\section{INTRODUÇÃO}

Na contemporaneidade, os espetáculos de dança constituem uma construção artística colaborativa resultante das "relações dialógicas entre concepção, iluminação, ambientação, sonorização, figurino, partituras corporais e outros." (SAMPAIO, 2011, p.10) Trata-se de construções que exigem cuidadoso planejamento prévio e que envolvem conteúdos multidisciplinares fazendo convergir competências de diferentes profissionais, extrapolando inclusive, a noção hierárquica que prioriza o movimento do bailarino.

A cenografia é parte essencial de qualquer produção artística que precisa de ambientação para a sustentação de seu discurso. No caso dos espetáculos de dança, a cenografia irá correlacionar o espaço com o corpo do bailarino tornando, assim, os demais elementos cênicos como painéis de fundo, iluminação e objetos em projeções do discurso oriundo do corpo em movimento.

A confirmação do caráter projetual da produção cenográfica de um espetáculo, ao aproximar a cenografia do design, abre inúmeras possibilidades de atuação para os profissionais desta área.

O caráter multidisciplinar do design tem permitido que os profissionais da área transitem com certa desenvoltura em diferentes campos de atuação. Não é incomum, no entanto, as concepções restritivas que ainda veem o design apenas como um componente estético dos objetos. Se por um lado, aumentam os argumentos que ampliam a esfera de atuação do profissional de design, ainda pouco se têm escrito, de fato, sobre tais possibilidades e como elas se configuram diante do campo formativo.

O desconhecimento de possibilidades alternativas de atuação profissional, ou o entendimento muitas vezes equivocado de que algumas atividades não constituiriam objeto de trabalho do design e sim do campo da arte, pode ser um fator desestimulador de trajetórias profissionais.

Se no exterior (entenda-se América do Norte e Europa, principalmente) já existe a compreensão do papel fundamental do designer na concepção, desenvolvimento, materialização e até mesmo gestão de espetáculos (como Tim Hatley e Hugh Vanstone da equipe de Design do Royal Opera House), o mesmo não ocorre ainda no Brasil e este trabalho pretende, portanto, contribuir para esclarecer a questão bem como oferecer àqueles que atuam na área, outras possibilidades de atuação profissional.

A questão de pesquisa que orientou o presente de trabalho foi a identificação de quais os indícios que caracterizam a cenografia como atividade de design e qual sua função na cena da dança.

A hipótese é que a cenografia de um espetáculo de dança consiste em um projeto e como tal envolve procedimentos metodológicos que a configuram como atividade de design e coautora da cena de dança, por constituir parte integrante de sua concepção e colaborar na construção de sentidos da composição artística.

Para a verificação da hipótese foi traçado como objetivo geral a identificação dos pontos em comum entre o projeto cenográfico e o projeto de design por meio do confronto de literatura específica sobre as duas áreas e análise da obra de balé de repertório "Don Quixote". 


\section{DESENVOLVIMENTO}

\subsection{Métodos e Procedimentos}

A opção foi pela metodologia com enfoque qualitativo do tipo descritivo e explicativo. Na primeira etapa o objetivo foi identificar na literatura sobre cenografia os indícios que a correlacionem a um projeto de design. Foi realizada, então, a ampliação da revisão bibliográfica de modo a aprofundar a compreensão dos diferentes conceitos envolvidos - cenografia, design, dança, balé de repertório, e buscar os pontos de convergência que confirmem a concepção cenográfica como uma atividade projetual de design.

Na segunda etapa, com o objetivo de identificar as formas de interação entre o cenário, tema e coreografia do espetáculo foram descritas e analisadas duas produções de uma obra de balé de repertório de modo a se comparar ambas para distinguir um projeto cenográfico de uma concepção artística cenográfica. $O$ paralelo entre as produções abre nossa visão para compreender o papel da cenografia como coautora do espetáculo na medida em que contribui para a construção do sentido da apresentação. A escolha da obra "Don Quixote" feita pelo Royal Ballet de Londres em paralelo com a produção do Teatro Municipal do Rio de Janeiro se justifica por tratarse de uma peça de 'balé de repertório' e haver material fotográfico, videográfico e pessoal de produtores acessível para fazê-lo. Além disso, o balé de repertório traz consigo a proposta de inovação na cenografia da obra sem perder a coerência e fidelidade ao libreto original, permitindo a ação progressiva de fazer com que o projeto cenográfico possa dar mais sustentação ao discurso da obra e ter a sua relação de coautora na obra em geral.

Os procedimentos para a análise da obra consistirão em:

- Descrição e análise estrutural e estética das 'cenas de dança' (consideradas por cena);

- Discussão sobre as relações criadas entre o cenário, a coreografia e o tema do espetáculo evidenciando o impacto do cenário no conjunto da peça.

- Para análise da obra escolhida serão utilizadas, ainda, outras informações presentes na mídia sobre a mesma como o libreto da versão reproduzida hoje em dia, sites referentes a indústrias que produziram o cenário da obra, críticas sobre as novas produções e documentação fotográfica.

- Na etapa de conclusão será feita a convergência dos elementos identificados para a construção do conceito de cenografia como design cenográfico.

\subsection{Revisão de Literatura}

O desenvolvimento do trabalho incluiu a leitura de publicações ou autores que pudessem contribuir para o entendimento da área de interesse, a identificação do problema bem como a verificação da hipótese e direcionamento dos trabalhos.

Roubine (1998) traz a cenografia para a dança, principalmente em relação às desconstruções dentro do formato dos balés românticos em todos os aspectos da produção, sofreu mudanças em relação às interações entre bailarinos e cenário no início do século XX com os Ballets Russes de Serge Diaghlev e acaba por focar-se na representação baseada em painéis pictóricos pintados por artistas deixando o espaço cênico para a performance dos bailarinos em cena. Também discute a relação que a 
dança toma em relação à cenografia pictográfica que nos revelará a importância dada à figura do pintor reafirmando seu envolvimento íntimo com a obra em forma de sua expressão inspirada e contextualizada pela obra.

Assim, Roubine (1998) reafirma a fala de Noverre (2006, p. 228) em que se compara a cena de dança com um quadro em toda a sua manifestação visual para com o expectador ao perceber o espetáculo como essa obra pictórica.

\footnotetext{
Um balé é o quadro, a cena é a tela, os movimentos mecânicos dos figurantes são as cores; se me permitis, direi que suas fisionomias são o pincel, o conjunto e a vivacidade das cenas, a escolha da música, o cenário e o figurino são o seu colorido; enfim o compositor é o pintor. (NOVERRE, 2006, p. 229)
}

Segundo Scapin Jr.(2011) o comportamento humano num contexto onde serviços e produtos procuram solucionar necessidades (desejos) de seus consumidores, apresenta certa volatilidade. Inovação, criatividade e ousadia definem suas escolhas.

O design fará interfaces com diversas áreas do conhecimento pelo seu caráter projetual, ou seja, toda atividade que exige planejamento para certo fim é um processo de design.

$\mathrm{Na}$ busca de resultados compatíveis com o contexto da contemporaneidade, o design não se esgota por si só, ele transcende seu 'lugar comum' e abrange todo tipo de atividade projetual carregada de um discurso a ser transmitido.

A leitura das tendências da contemporaneidade e das questões ambientais imersas nela é essencial para o designer cenográfico que deve, também, entender o processo de desenvolvimento de um projeto cenográfico em toda a sua abrangência, desde suas primeiras referências e aprofundamento da pesquisa, até a concretização da cenografia completa.

Vemos que, na concepção do projeto cenográfico, o designer volta o olhar para o principal agente indutor do processo criativo para a geração de um produto: o público. Este público terá uma relação de cumplicidade e interatividade com o espetáculo e a cenografia criará o ambiente para que isso aconteça. A plateia vivenciará uma troca de sentimentos e emoções com a obra e a parte técnica será fruída de forma velada.

O aspecto da fruição de forma velada pelo público nos traz mais uma característica do design que é substituir o que é natural pelo artificial gerando novos objetos e novas formas de uso, apresentando, assim, a "farsa", a "trama", a "ficção" como elementos presentes simultaneamente na arte. Dessa forma, o design cenográfico irá concretizar o imaterial, ou seja, ele dará forma ao ambiente que pairava sobre a obra, tornará tátil, visível, perceptível, o contexto do espetáculo fazendo-o tornar-se um fenômeno.

O design, como todas as expressões culturais, mostra que a matéria não aparece, a não ser que seja informada, e assim, uma vez informada, começa a se manifestar. A matéria no design, como em qualquer outro aspecto cultural, é o modo como as formas aparecem. (FLUSSER, 2008, p.28)

O fator que irá possibilitar a concretização do imaterial é a plasticidade do espaço cênico que é físico e, ao mesmo tempo, mutável. Sua dimensão possibilita uma exploração ilimitada de tudo o que ecoa em torno do tema proposto. 0 design 
cenográfico permite que o projeto surja em meio ao contexto ilimitado através de pesquisas históricas, ambientais e iconográficas; interpretação visual da realidade; análise técnica de viabilidade de concretização das ideias. Esses três aspectos irão dar base ao processo criativo do design cenográfico que fará com que a visualidade cênica crie o ambiente lúdico que sustenta a linguagem dramática que dialoga com a plateia. Os métodos próprios do design agem como referências norteadoras e essenciais para a amplificação das possibilidades de criação no espaço cênico. O design viabiliza a produção pelos seus critérios, abrangência de pesquisas e estudos e pelas metas e prazos.

Na leitura de Brewster e Shafer (2011) vimos que um designer cenográfico deve possuir habilidades que vão além das existentes no universo do design, seu entendimento engloba a produção teatral, as formas colaborativas de concepção ao longo dessa produção, as técnicas inerentes ao contexto teatral e a capacidade de dar vida ao projeto. Destacam que a curiosidade investigativa sobre tudo o que engloba a história a ser contada, como cultura, sociedade e vivências locais dá forma à cenografia.

O cenário cria o ambiente físico da ação da peça, por isso, os objetivos da produção do design cenográfico são o lugar e a localidade. Isso é determinante para a movimentação dos atores, por isso se deve conceber um layout do cenário que dará noção para a ação a ocupar e garantirá que a primeira impressão da plateia ao ver o projeto final coincida com o estilo do desempenho. Também ocorre essa interação do espaço físico na dança de forma bem evidente, pois os elementos clássicos da cenografia se fundamentam na manutenção do espaço central para a livre movimentação dos bailarinos, na utilização de planos de fundo, painéis de composição ambiental, iluminação, dando, assim, perspectiva que cria a ilusão de amplitude ao público. As produções que envolvem uma base com lugar, localidade, tempo e período apresentam força e dão base sólida para a materialização destes elementos projetados pelo designer cenográfico. O uso de objetos fiéis ao contexto apresentado é mais uma ferramenta para a geração do sentido proposto na peça. Quando algum destes elementos não se faz presente no roteiro da produção, se faz necessário que a equipe de designers envolvidos chegue a um consenso de como inserir, ou não, tais elementos.

Para o desenvolvimento cenográfico também se faz necessário considerar os aspectos objetivos que sustentarão o campo semântico da peça, o modo, o tema e o estilo. Sem esses elementos bem estabelecidos e traduzidos a peça pode estar confusa e ambígua. Os caracteres visuais e tangíveis do cenário são determinantes para a comunicação do caráter da peça, de seu estilo e para embasar e sustentar o proposto tema. Estes elementos sensoriais transportam a plateia para a "realidade" proposta mantendo a coerência e a identidade da peça.

Ampliando ainda mais a abrangência do design cenográfico, Brewster e Shafer(2011) destacam que o cenário também deve revelar os personagens da peça. Essa revelação do personagem através do espaço físico irá envolver a plateia na história a ser contada. O design cenográfico considera estes aspectos como ideais na concepção do cenário desde a pesquisa e análise de tudo isso que refletirá no produto final.

Para desenvolver uma concepção cenográfica realista deve-se voltar o olhar para o local atual onde a história acontece, porém em concepções não realistas devem 
ter um aprofundamento adicional nas características particulares do estilo da peça, não é apenas o local, mas também as relações de como o sentido subjetivo são relacionados com os elementos de design aplicados na arte expressionista. Também existem problemas práticos de efeitos solicitados pelo script, como efeitos de ordem imaterial ou sobrenatural, que devem ser estudados e resolvidos para a sustentação da história. Nestes problemas devem-se considerar as limitações de espaço físico, tempo, trabalho e dispositivos. A ilusão dada ao público através de tais efeitos deve ser "mágica", por isso é necessário o levantamento das possibilidades de movimentação de peças cenográficas e efeitos visuais sobre as mesmas.

Além das leituras específicas sobre cenografia foram buscados conteúdos que abordassem o design de modo mais geral e, nesse sentido, os dois autores consultados foram Burdek (2006) e Baxter (1998).

Burdek apresenta um conjunto bastante diversificado de informações, mas especialmente ao abordar os aspectos metodológicos e teóricos do design oferece aspectos que vão ao encontro deste trabalho.

Cada objeto de design é o resultado de um processo de desenvolvimento,
cujo andamento é determinado por condições e decisões - e não apenas
por configuração. Os desenvolvimentos socioeconômicos, tecnológicos e
especialmente os culturais, mas também os fundamentos históricos e as
condições de produção técnica têm papel importante, assim como os
fatores ergonômicos ou ecológicos com seus interesses políticos e as
exigências artístico-experimentais. (BURDEK, 2006, p. 225)

Ao salientar "[...] que os projetos de produtos não precisam atender apenas a fatores ergonômicos, construtivos, técnicos de fabricação, econômicos ou ecológicos" (Ibidem, p. 231), incluir os significados emocionais e expressivos resultantes dos aspectos perceptivos, comunicacionais e semióticos e principalmente afirmar que "Design é uma disciplina que não produz apenas realidades materiais, mas especialmente preenche funções comunicativas" (Ibidem, p.230), o autor sinaliza para a possibilidade de estender-se a ação do design ao planejamento e projeto de um cenário, entendido este como um espaço primordialmente comunicacional no contexto de um espetáculo.

Baxter traz a visão do designer como um profissional multifuncional capaz de se adaptar a áreas promissoras que tenham a oportunidade de atuação relacionando, assim, a abordagem interdisciplinar, o que pode relacionar o projeto cenográfico ao design considerando a multifuncionalidade e a interdisciplinaridade do profissional que atua nesse tipo de produção.

Os métodos sistemáticos de um projeto exigem uma abordagem interdisciplinar, abrangendo métodos de marketing, engenharia de métodos e a aplicação de conhecimentos sobre estética e estilo. Esse casamento entre ciências sociais, tecnologia e arte aplicada nunca é uma tarefa fácil, mas a necessidade de inovação exige que seja tentada.

Os melhores designers do futuro serão multifuncionais e se sentirão à vontade discutindo pesquisa de mercado, fazendo um rendering a cores de um novo produto ou selecionando o tipo de material que deve ser usado no produto. O mais importante é ter conhecimentos básicos e metodológicos para o desenvolvimento de novos produtos, para coordenar as atividades de projeto. (BAXTER, 1998, p. 3) 
Ainda nos chama atenção para a presença da arte no projeto, trazendo assim, mais um fato que confirma o projeto cenográfico como design, relacionando-o com o casamento entre a mesma, as ciências sociais e a tecnologia, elementos estes que se fazem presentes no produto cenográfico. Ao pontuar as competências do deigner do futuro, também reforça, mais uma vez, como que a atuação do mesmo se projeta para englobar diversas áreas de produção tornando-as atividades de design.

Voltando o olhar para dois outros autores que também representam a visão metodológica do Design, Bonsiepe e Munari, podemos destacar Bonsiepe (1984, p. 10) em sua afirmação sobre o processo projetual como o método disciplinado de pensamento, o que nos abre a 23 visão sobre o processo de concepção e materialização de uma produção cenográfica em um espetáculo.

O processo projetual é - ou deveria ser - um processo de pensamento disciplinado, que se caracteriza pela grande agilidade de passar de um problema parcial a outro problema parcial, avaliando as implicações de um sobre o outro. (BONSIEPE, 1984, p. 10)

Munari (2001, p. 21) vêm confirmar o método projetual de forma abrangente afirmando que "criatividade não significa improvisação sem método", o pensamento hierárquico e as etapas processuais, desde que feitas de forma organizada, podem se apresentar com alto grau de criatividade visto que: "o método projetual para o designer não é nada de absoluto nem definitivo; é algo que se pode modificar se se encontrarem outros valores objetivos que melhorem o processo." (MUNARI, 2001, p. 21)

Isso nos mostra que o designer tem liberdade para atuar em diversas áreas adaptando sua metodologia através dos métodos de design aplicados de acordo com o seu projeto, fato que engloba a produção cenográfica como, também, uma área de projeto de design onde se aplica métodos de otimização, concepção e desenvolvimento de produtos comunicativos com aspectos semânticos, funcionais e estéticos na produção de um espetáculo.

\subsection{Análises das Produções Cenográficas do Balé de Repertório Don Quixote}

O caso em estudo será a produção cenográfica do Balé de Repertório Don Quixote realizado pela companhia Royal Ballet de Londres e a produção do mesmo espetáculo realizado pela companhia do Theatro Municipal do Rio de Janeiro.

Para maior compreensão do contexto da produção cenográfica do balé analisado, serão apresentados dados sobre as representações das releituras do cenário dessa obra.

\subsubsection{Descrição das Produções Escolhidas}

As montagens escolhidas para análise foram a de 2014 de Carlos Acosta para o Royal Ballet de Londres e a de Dalal Achcar de 2010 para o Theatro Municipal do Rio de Janeiro com ficha técnica apresentada a seguir: 
Tabela 1 - Ficha Técnica das Obras Escolhidas.

\begin{tabular}{lll}
\hline Produção & Royal Ballet de Londres & $\begin{array}{l}\text { Theatro Municipal do Rio } \\
\text { de Janeiro }\end{array}$ \\
\hline Direção Artística & Carlos Acosta & Dalal Achcar \\
\hline $\begin{array}{l}\text { Música e } \\
\text { Musicais }\end{array}$ & $\begin{array}{l}\text { Ludwig Minkus e Martin } \\
\text { Yates }\end{array}$ & $\begin{array}{l}\text { Ludwig Minkus e Patrick } \\
\text { Flynn }\end{array}$ \\
\hline Cenografia & Tim Hatley & José Varona \\
\hline lluminação & Hugh Vanstone & José Luis Fiorruccio \\
\hline
\end{tabular}

Fonte: Elaborado pelo autor, com base na pesquisa realizada.

\subsubsection{Comparação das Obras Escolhidas}

As produções escolhidas foram comparadas em grau de complexidade do processo de concepção tanto da cenografia de caráter projetual da produção do Royal Ballet de Londres (FIG. 3) quanto na cenografia de caráter intuitivo da produção do Theatro Municipal do Rio de Janeiro (FIG. 4). Sendo assim a comparação estabelecerá um paralelo entre as produções distinguindo aspectos relativos às técnicas utilizadas, às interações com os bailarinos em cena, aos valores discursivos apresentados na obra e à fidelidade com o repertório revelada pela cenografia.

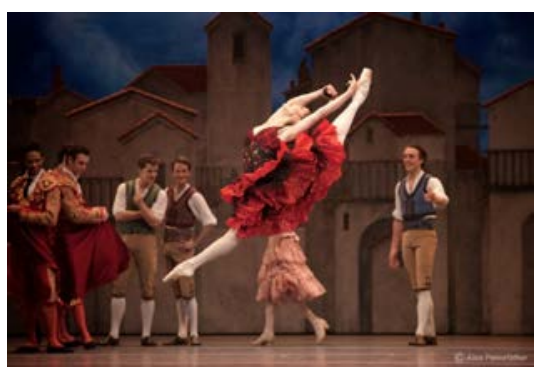

Figura 1 - Variação "desafio de Kitri" (Royal Ballet). Fonte: PENNEFATHER, 2014

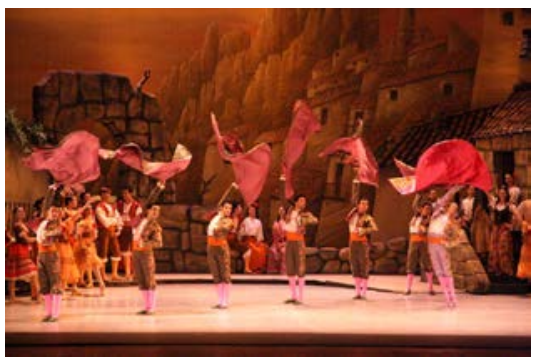

Figura 2 - Toureiros na praça de Sevilla (Theatro Municipal) Fonte: Acervo pessoal de Dalal Achcar

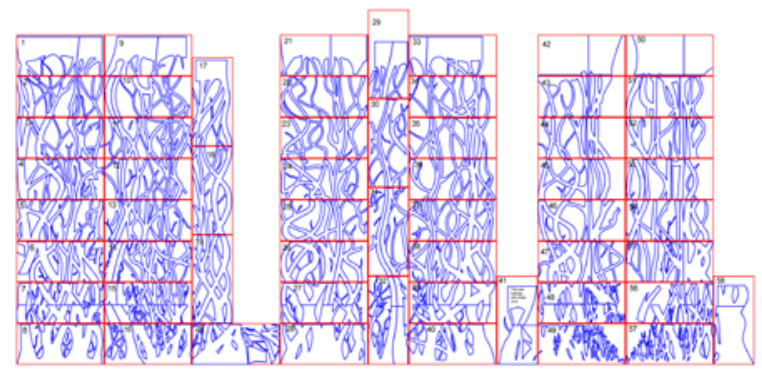

Figura 3 - Representação em plataforma digital do cenário do ato II (Royal Ballet) Fonte: desenvolvido pela empresa HYDROMAR para o Royal Ballet Theatre, 2013. 


\begin{tabular}{|c|c|c|}
\hline PRODUÇÃO & ROYAL BALLET DE LONDRES & $\begin{array}{l}\text { THEATRO MUNICIPAL DO RIO DE } \\
\text { JANEIRO }\end{array}$ \\
\hline PRÓLOGO & $\begin{array}{l}\text { Composição: três painéis de fundo } \\
\text { onde o terceiro limita o fundo do } \\
\text { quarto com a porta de entrada. } \\
\text { Elementos como cama, cômoda, } \\
\text { aquecedor, cadeira e objetos de } \\
\text { composição (livros, castiçais, crucifixo, } \\
\text { tecidos, etc) são encontrados no } \\
\text { mesmo; Diferencial: partes do cenário } \\
\text { que se transformam em objetos } \\
\text { manuseados pelos bailarinos. }\end{array}$ & $\begin{array}{l}\text { Composição: um painel introdutório de } \\
\text { fundo onde se passará a cena e objetos } \\
\text { característicos do personagem (lança, } \\
\text { elmo e espada); Diferencial: } \\
\text { representar o universo íntimo de Don } \\
\text { Quixote expresso apenas no painel de } \\
\text { fundo. }\end{array}$ \\
\hline ATO I & $\begin{array}{l}\text { Composição: diversos painéis que } \\
\text { representam as residências, } \\
\text { estabelecimentos e instalações locais } \\
\text { de Sevilla, sendo todos móveis e, } \\
\text { como plano de fundo, a } \\
\text { representação de um céu feita pelo } \\
\text { ciclorama. Existem objetos cênicos } \\
\text { como mesas, bancos, cadeiras, cestos } \\
\text { de frutas e flores, instrumentos } \\
\text { musicais. Diferencial: movimentação } \\
\text { dos painéis adaptando o espaço do } \\
\text { palco para o tipo de uso que o } \\
\text { bailarino fará do mesmo. }\end{array}$ & $\begin{array}{l}\text { Composição: plano de fundo pintado } \\
\text { representando edificações e } \\
\text { montanhas da cidade como se estivesse } \\
\text { ao fundo de uma página de livro } \\
\text { rasgada, uma plataforma central que } \\
\text { porta um único painel limitando a } \\
\text { entrada da Praça de Sevilla, dois painéis } \\
\text { em perspectiva, uma moldura } \\
\text { representando o painel introdutório } \\
\text { rasgado como mais uma página da } \\
\text { história e objetos cenográficos como } \\
\text { mesas, cadeiras, bancos, xales } \\
\text { pendurados nas varandas e alimentos } \\
\text { para a interação direta com os } \\
\text { bailarinos. Diferencial: espaço } \\
\text { performático amplo para as virtuoses } \\
\text { dos bailarinos. }\end{array}$ \\
\hline $\begin{array}{l}\text { ATO II - CENA DO } \\
\text { ACAMPAMENTO CIGANO }\end{array}$ & $\begin{array}{l}\text { Composição: mesmo ciclorama do } \\
\text { primeiro ato, por um painel } \\
\text { representando a silhueta do moinho } \\
\text { de vento, árvores secas em planos } \\
\text { diferentes que se repetem } \\
\text { enfileiradas em diferentes painéis e } \\
\text { objetos cenográficos como } \\
\text { instrumentos musicais, bancos e } \\
\text { cadeiras para composição da cena. } \\
\text { Diferencial: objetos cenográficos } \\
\text { trazidos e levados de cena pelos } \\
\text { bailarinos. }\end{array}$ & $\begin{array}{l}\text { Composição: seque o formato geral do } \\
\text { primeiro ato, o painel de fundo possui a } \\
\text { pintura de moinhos de vento e de uma } \\
\text { página rasgada como moldura da } \\
\text { imagem, com uma pequena } \\
\text { representação de uma árvore seca na } \\
\text { extremidade inferior da direita do } \\
\text { painel. Existem mais duas molduras de } \\
\text { páginas rasgadas para estabelecer a } \\
\text { impressão de profundidade. Outro } \\
\text { elemento é representado pelas } \\
\text { carroças em madeira além de outros } \\
\text { objetos cenográficos para a } \\
\text { sustentação do discurso. Diferencial: } \\
\text { personagens que interagem com as } \\
\text { carroças dispostas em cena. }\end{array}$ \\
\hline $\begin{array}{l}\text { ATO II - CENA DO JARDIM } \\
\text { DAS DRÍADES }\end{array}$ & $\begin{array}{l}\text { Composição: semelhante à cena } \\
\text { anterior, porém, composto por novos } \\
\text { painéis que representam flores } \\
\text { gigantes; Diferencial: movimentação } \\
\text { dos painéis de acordo com o } \\
\text { movimento do bailarino no espaço. }\end{array}$ & $\begin{array}{l}\text { Composição: o painel de fundo da cena } \\
\text { anterior que representava os moinhos } \\
\text { de vento e as páginas rasgadas } \\
\text { permanece; Diferencial: amplitude do } \\
\text { espaço para a performance do corpo de } \\
\text { baile. }\end{array}$ \\
\hline
\end{tabular}




\begin{tabular}{|c|c|c|}
\hline $\begin{array}{l}\text { ATO III - CENA DA } \\
\text { TABERNA }\end{array}$ & $\begin{array}{l}\text { Composição: uma gama de objetos } \\
\text { cênicos que contextualizam o } \\
\text { ambiente da taberna, plataformas } \\
\text { com escadas para a entrada dos } \\
\text { personagens, mesas, balcões, } \\
\text { cadeiras, bancos, colunas de } \\
\text { sustentação, cortinas e janelas; } \\
\text { Diferencial: interações dos bailarinos } \\
\text { com o cenário em momentos de } \\
\text { virtuosismo em cima de plataformas. }\end{array}$ & $\begin{array}{l}\text { Composição: recursos que dialogam } \\
\text { com a cenografia do primeiro ato de } \\
\text { forma que as cores são similares, os } \\
\text { painéis seguem o mesmo caminho das } \\
\text { áreas externas e muitos objetos } \\
\text { cenográficos são representados em } \\
\text { pintura no próprio painel, sendo poucos } \\
\text { objetos reais de interação com os } \\
\text { personagens e corpo de baile; } \\
\text { Diferencial: ênfase nos bailarinos e seus } \\
\text { virtuosismos com alguns objetos } \\
\text { cenográficos como canecos e taças. }\end{array}$ \\
\hline $\begin{array}{l}\text { ATO III - CASAMENTO NA } \\
\text { PRAÇA DA CIDADE }\end{array}$ & $\begin{array}{l}\text { Composição: mesma cenografia da } \\
\text { cena do primeiro ato, pois estão de } \\
\text { volta à Praça de Sevilla, porém os } \\
\text { umbrais das portas das edificações, } \\
\text { janelas e varandas são decoradas com } \\
\text { flores, arranjos e fitas. O cenário } \\
\text { cumpre a função de contextualizar o } \\
\text { casamento de Kitri e Basílio; } \\
\text { Diferencial: movimentação dos } \\
\text { painéis abrindo o caminho para que } \\
\text { Don Quixote parta ao anoitecer. }\end{array}$ & $\begin{array}{l}\text { Composição: mesma cenografia do } \\
\text { primeiro ato com pequenas alterações } \\
\text { referentes à contextualização do } \\
\text { casamento de Kitri e Basílio como } \\
\text { arranjos de flores nas edificações e } \\
\text { lustres envolvendo a moldura de papel } \\
\text { representando a temporalidade da } \\
\text { partida de Don Quixote pelo anoitecer; } \\
\text { Diferencial: valorização da composição } \\
\text { cenográfica da Praça de Sevilla pelos } \\
\text { arranjos de flores. }\end{array}$ \\
\hline
\end{tabular}

Fonte: Elaborado pelo autor, com base na pesquisa realizada.

\section{CONCLUSÃO}

O confronto dos autores mencionados durante o estudo revelou que existe a concepção de cenário como obra de arte - principalmente quando este se coloca como um elemento exclusivamente de contextualização, mas revelou também como vários autores entendem a concepção cenográfica como um projeto mais complexo e, nesse caso, mais afeito à ação do designer.

A análise comparativa desenvolvida entre duas montagens, uma inglesa e outra brasileira, do mesmo balé de repertório, evidenciou que existem diferenças na forma de se pensar e trabalhar a cenografia. De modo simplificador, pode-se dizer que existem concepções cenográficas de viés artístico - como naquela do Theatro Municipal, e concepções cenográficas como um projeto de design, como na do Royal Ballet.

Em produções, como do Royal Ballet, nas quais é objetivada a interação entre os bailarinos e o cenário, a concepção cenográfica se utiliza de ferramentas e atributos mais próximos ao design. Os diferentes espaços da cena são planejados de modo a permitir não apenas o movimento dos corpos, mas também a interação dramática entre a cena, os objetos nela presentes e os bailarinos. Nesse sentido, a concepção do(s) cenário(s) precisa recorrer a métodos de projeto bem como incluir preocupações com a seleção de materiais, formas e tamanhos que permitam a adequada visualidade, o manuseio fácil e ágil na troca de cenários, a segurança e conforto dos bailarinos, a adequada condição de transporte (para outros locais de espetáculo) e principalmente, a capacidade de interlocução do arranjo da cena com o tema e movimentos pretendidos.

Nas produções, como no caso do Theatro Municipal, para as quais a ênfase é no desempenho dos bailarinos, tais considerações não são relevantes uma vez que o 
cenário se restringe a um plano de fundo com o objetivo único de contextualização da ação e sem pretender interações muito intensas entre cenário e bailarinos para que o virtuosismo performático dos mesmos fique evidente.

O presente estudo não faz nenhum juízo da qualidade dos espetáculos. Ambas as produções são bem sucedidas e demonstram fidelidade e coerência em relação ao balé de repertório Don Quixote, no entanto oferecem resultados distintos que dependem do modus operandi de cada companhia teatral. O que o trabalho procurou estabelecer é que há diferenças entre cenários concebidos como um projeto e cenários concebidos como uma expressão artística e que, no caso dos primeiros, abrese um significativo espaço de trabalho para o profissional do design atuar na concepção cenográfica quando esta concepção objetivar interlocução intensa entre o espaço e o artista.

O projeto cenográfico de um espetáculo, desde sua idealização até o momento de materialização da produção, pode apresentar, conforme o caso, elementos estruturais e metodológicos muito próximos ao projeto de design. Nesse caso, o cenógrafo é o profissional que apresentará expertises de caráter multidisciplinar e visão do processo de concepção como um todo, assim como o profissional de design. As técnicas e tecnologias que já existem unidas às competências e habilidades do profissional de design especializado em cenografia dão margem a produções que permitem a interação do bailarino com o cenário e coerência para os balés que são reproduzidos ao longo da história.

\section{REFERÊNCIAS}

ACHCAR, Dalal. Balé: uma arte. Rio de Janeiro: Ediouro, 1998.

AQUINO, Stela Gonçalves; SCHWARTZ, Rosana Maria. A Influência do Ballet de Repertório do Século XIX no Imaginário Feminino. In: JORNADA DE INICIAÇÃO CIENTífICA, 7, 2011, São Paulo. Anais da VI Jornada de Iniciação Científica. São Paulo, Universidade Presbiteriana Mackenzie, 2012. Disponível em: Acesso em abril/2015.

BAXTER, Mike. Projeto do Produto: Guia prático para o desenvolvimento de novos produtos. São Paulo: Edgard Bluncher, 1998. 260 p.

BÓGEA, Inês. Contos do Balé. São Paulo: Cosacnaify, 2007. 80 p.

BONI, Claudio Roberto; SILVA, Kelenson; SILVA, José Carlos Plácido da. Os Limites do Design e a Relação com a Arte e a Indústria. In: 11 CONGRESSO DE PESQUISA E DESENVOLVIMENTO EM DESIGN. Gramado, 2014. Disponível em: Acesso em Junho de 2015.

BONSIEPE, Gui. Metodologia experimental: design industrial / coordenação Gui Bonsiepe - Brasília: CNPq/Coordenação Editorial, 1984.

BOURCIER, Paul. História da Dança no Ocidente. São Paulo: Martins Fontes, 2001. 340 p.

BREWSTER, Karen; SHAFER, Melissa. Fundamentals of Theatrical Design. Ney York: Allworth Press, 2011.

BURDEK, Bernhard E. História, teoria e prática do design de produtos. São Paulo: Blucher, 2006, $496 \mathrm{p}$. 
DEL NERO, Cyro. Cenografia: uma breve visita. São Paulo: Claridade, 2008, 96 p.

DON QUIXOTE. Direção: Ross MacGibbon. Produção: Carlos Acosta. Londres (UK): Opus Arte, 2014, 1 DVD.

FLUSSER, Vilém. O mundo codificado: por uma filosofia do design e da comunicação. São Paulo: Cosac Naify, 2008, 222 p.

HYDROMAR. Royal Opera House Don Quixote. Disponível em:. Acesso em: 01/06/2015. LIMA, Wlad. Glossário de Termos Técnicos de Teatro. Disponível em: Acesso em outubro 2015.

LUCIANI, Nádia Moroz. Design cênico: um caminho possível para a criação da luz e a formação do iluminador. In: A LUZ EM CENA - ENCONTRO CATARINENSE DE ILUMINAÇÃO CÊNICA, 5, 2013, Florianópolis. Anais do V Encontro Catarinense de Iluminação Cênica. Florianópolis, UDESC, 2013. Disponível em Acesso em maio de 2015.

MONTEIRO, Marianna. Noverre: Cartas sobre a dança. 1 ed. 1 reimpr. São Paulo: EDUSP/FAPESP, 2006, $400 \mathrm{p}$.

MUNARI, Bruno. Das Coisas Nascem Coisas. São Paulo: Martins Fontes, 2001.

PENNEFATHER, Alice. Don Quixote Royal Opera House. Disponível em:. Acesso em: 01/06/2015.

RATTO, Gianni. Antitratado de Cenografia: variações sobre o mesmo tema. São Paulo: SENAC, 1999, $188 \mathrm{p}$.

REYNOLDS, Nancy. Repertory in Review: 40 years for the New York City Ballet. New York: Dial Press, 1977.

ROUBINE, Jean-Jaques. A linguagem da encenação teatral - 1880-1980, tradução e apresentação. Yan Michalski.2ed. Rio de Janeiro: Jorge Zahar, 1998.

SAMPAIO, Flaviana Xavier Antunes. A dança contemporânea em foco: a iluminação como coautora da cena. 2011. 143 fls. Dissertação (Mestrado em Dança) - Escola de Dança, Universidade Federal da Bahia, Salvador, 2011.

SCAPIN JR., Ary. O design cênico do circo: um olhar para o processo projetual. 2011. 139 fls. Dissertação (Mestrado em Design) Universidade Anhembi-Morumbi, São Paulo, 2011.

SILVA, Eliana Rodrigues. Encenação e Cenografia para Dança. Diálogos Possíveis: revista da Faculdade Social da Bahia. Salvador, v.10, 18-32, jan-jun 2007. Disponível em Acesso em abril 2015. 